Texas A\&M University-San Antonio

Digital Commons @ Texas A\&M University- San Antonio

Special Education Faculty Publications

College of Education and Human Development

6-2019

\title{
Planning and Implementing Student-Led IEPs for Students With EBD
}

Mariya T. Davis

Texas A\&M University-San Antonio, Mariya.Davis@tamusa.edu

Ingrid K. Cumming

Orange County Public Schools

Follow this and additional works at: https://digitalcommons.tamusa.edu/sped_faculty

Part of the Disability and Equity in Education Commons, and the Special Education and Teaching

Commons

\section{Repository Citation}

Davis, Mariya T. and Cumming, Ingrid K., "Planning and Implementing Student-Led IEPs for Students With EBD" (2019). Special Education Faculty Publications. 1.

https://digitalcommons.tamusa.edu/sped_faculty/1

This Article is brought to you for free and open access by the College of Education and Human Development at Digital Commons @ Texas A\&M University- San Antonio. It has been accepted for inclusion in Special Education Faculty Publications by an authorized administrator of Digital Commons @ Texas A\&M University- San Antonio. For more information, please contact deirdre.mcdonald@tamusa.edu. 
Planning and Implementing Student-led IEPs for Students with EBD

Mariya T. Davis, Ph.D.

Texas A\&M University San Antonio

College of Education and Human Development

One University Way, San Antonio, Texas 78224

Ingrid K. Cumming, Ed.D.

Orange County Public Schools

550 S. Eola Drive

Orlando, FL 32801 


\section{Planning and Implementing Student-led IEPs for Students with EBD}

Eric is a 17-year-old high school junior who enjoys football, tennis, and automobiles.

Eric has been receiving special education services in general education classes as a student with an emotional disturbance since he was in fourth grade. An Individualized Education Program (IEP) has been implemented to address Eric's behavioral and social-emotional needs often exhibited by agitation, withdrawal, and a reliance on others to coach him in new situations. As Eric's junior year is coming to a close, he becomes increasingly anxious about his plans after graduation. Eric has been dreaming what he would like to do after school, but is uncertain what the future holds and doubtful about being prepared to enter the workforce. Eric has been sharing his career interests and goals with his parents and IEP case manager Mr. Adams. But Eric is apprehensive about completing a task that Mr. Adams his given him, which is to help lead the upcoming transition IEP meeting. He lacks confidence presenting and speaking in front of people, especially adults. Still, Eric agrees with Mr. Adams and his parents that he needs to have the opportunity to practice public speaking and advocate for his needs.

The Individuals with Disabilities Education Act (IDEA) requires the provision of transition services to students with disabilities in order to prepare them for adulthood (IDEA, 2004). That population of students includes youth like Eric, who is verified with emotional disturbance, hereafter referred to as emotional and behavioral disorders (EBD). While transition services for students with EBD have improved over the last three decades, postsecondary outcomes for students with EBD continue to pose concerns for youth, families, educators, and researchers (Wagner, 2014). Research indicates that students with EBD consistently experience dismal outcomes in the areas of employment, postsecondary education, and community 
involvement (Wagner, 2014). For many students with EBD, meaningful work, career preparation, college participation, and community engagement seem to be beyond their reach.

Educational attainment appears to be a feasible option for adolescents with EBD. However, students with EBD continue to participate in postsecondary education at a lower rate than their peers without disabilities or peers with other disabilities (Wagner, 2014). According to the National Longitudinal Transition Study-2 (NLTS2), only 34\% of students with EBD participated in postsecondary programs (Newman, Wagner, Cameto, \& Knokey, 2009) and only $35 \%$ of students with EBD enrolled in a postsecondary school earned a diploma (Wagner, 2014). As reported by the NLTS2, students with EBD are less likely to inform their postsecondary schools of a disability. That is, only $13 \%$ of students received accommodations that they were otherwise entitled (Newman et al., 2009).

Also of concern are employment rates among adolescents with EBD, which have declined significantly in the past 20 years (Wagner, 2014). According to the NLTS2, adolescents with EBD were less likely to be employed full time compared to those with other disabilities. Among those adolescents with EBD who had been out of high school up to four years, $42 \%$ were reported to work full time at their current or most recent job, $20 \%$ reported being employed longer than six months, and only $11 \%$ were able to hold their jobs for over a year. Interestingly, NLTS2 findings suggest that adolescents with EBD may be reluctant to disclose their disability in their workplaces. For example, more than $80 \%$ of employed adolescents with EBD reported that their employers were not aware of their diagnosis, and only $2 \%$ reported receiving some kind of accommodation on the job. These outcomes indicate a need for interventions to improve post-school employment experiences for adolescents with EBD. 
Although postsecondary education and competitive employment are crucial outcomes for adolescents with EBD, important aspects of both their community integration should not be overlooked. The review of rate and quality of community engagement among adolescents with EBD suggests they could benefit from opportunities to develop their independent skills. The majority of adolescents with EBD (92\%) report an annual income of $\$ 25,000$ or less per year and only $22 \%$ live independently 4 years after high school (Newman et al., 2009). Further, the NLTS2 found that becoming involved with the criminal justice system is more common for adolescents with EBD than those in other disability categories, which translates into personal and social costs, including disruption to adolescents' educational programs, work, and family life.

These data indicate the importance of better preparing students with EBD for transition to adulthood. Educators of students with EBD need efficient, research-based ways to promote transition-related skills and make data-based decisions that will lead to improved post-school experiences for these students. The purpose of this article is to present a student-centered practice called student-led Individualized Education Program (IEP) that educators can use to engage students in their IEPs, promote transition-related skills, and increase the likelihood of positive postsecondary outcomes for adolescents with EBD.

\section{Student-led IEP}

The federal special education law denotes that students need to actively participate in their IEP meeting to represent their needs, strengths, and preferences (20 U.S.C. $§ 1401(34)(b)$; Flexer, Baer, Luft, \& Simmons, 2008). Simply inviting students to their IEP meetings will not ensure that the transition activities are based on their individual needs and preferences (Mason, McGahee-Kovac, \& Johnson, 2004). While the law requires student participation whenever 
appropriate, researchers argue that the term "'whenever appropriate' means always" (Wehmeyer, 1998, p. 4.).

Student-led IEP is a student-centered and student-directed practice that empowers students to participate in their IEP meeting as contributors, participants, and most importantly as leaders. As the leader of the IEP meeting, the student guides the IEP team members through all components of the IEP process, including the development of personally meaningful postsecondary goals. The student actively participates in all five stages of the IEP process: developing background knowledge, planning, drafting, meeting to finalize the draft, and implementing the program (see Figure 1; Konrad, 2008). In this process, the student learns the purpose of the IEP meeting, the roles of the different IEP team members, related terminology, and critical skills needed in school and in life.

<INSERT FIGURE 1 HERE>

\section{Importance of Student-led IEP}

The importance of students' active participation in their IEPs should not be overlooked. When IEPs are developed without student participation, students may come to believe that important decisions about their education and their future will be made for them. Imagine an IEP meeting being a birthday party. All attendees are discussing the upcoming event, planning for it, sending invitations, and dividing the jobs, but nobody invites the child, or asks his theme and cake preferences (Van Dycke, Martin, \& Lovett, 2006). As this continues year after year, the child may think that the IEPs are not important at all. When the child grows and finally gets invited to his IEP meeting, he might not only be confused and unprepared, but scared. Student participation in their IEP meetings will promote their understanding of the IEP process and its 
purpose, increase their levels of engagement and motivation, and facilitate the development of self-determination skills (Arndt, Konrad, \& Test, 2006).

Self-determination and active IEP-meeting participation have been linked to improved postschool outcomes for students with disabilities and remain critical features of successful transition planning for students with EBD (Test, Mazzotti, et al., 2009; Trainor, Smith, \& Kim, 2012). Self-determination has been operationally defined as "the ability to make choices, solve problems, set goals, evaluate options, take initiative to reach one's goals, and accept consequences of one's actions" (Rowe et al., 2015, p. 121). Students with EBD who learned selfdetermination skills are more likely to achieve their postschool goals and engage in competitive employment (Bullis, Moran, Todis, Benz, \& Johnson, 2002). However, adolescents with EBD demonstrate low self-determination and self-advocacy skills and may be reluctant to disclose their disabilities at school and work (Carter, 2010). These findings suggest that students with EBD will benefit from self-determination instructional support while in school.

Preparing students to lead their IEP meetings provides a realistic opportunity to learn and practice self-determination, self-advocacy, and many other important life skills (Hawbaker, 2007). Student-led IEPs focus not only on skills critical for success in life, but many other skills directly or indirectly related to standards and the general education curriculum (e.g., reading, writing, math). In addition, student-led IEP teaches students to take ownership for their own education and demonstrate it at the IEP meeting (Mason et al., 2004). Student-led IEP is an effective way of helping students with EBD understand their disabilities and self-advocate for needed supports and services in school and beyond. Because students with EBD typically have little opportunity to be involved in setting their own IEP and transition goals (Snyder, 2002), 
active involvement in the IEP process helps increase the likelihood that student interests and preferences are represented, allowing them to identify meaningful postsecondary goals.

\section{Student-led IEP Research Evidence}

Research has documented a number of positive outcomes associated with student-led IEPs. For example, Mason, McGahee-Kovac, Johnson, and Stillerman (2002) used an instructional program titled Student-Led IEPs: A Guide for Student Involvement to increase high school students' participation in their IEP meetings. Some other examples reported by research include increased student contribution to the meetings, understanding of rights and accommodations, disability awareness, self-confidence, responsibility for themselves, awareness of their limitations, awareness of available resources, and parental participation (Konrad \& Test, 2004; Mason, et al., 2004; Snyder \& Shapiro, 1997). Research has also demonstrated that students can practice self-determined behaviors, such as self-awareness, choice making, goal setting, and self-advocacy, by learning to lead the IEP process (Arndt el al., 2006; Martin et al., 2006; Woods, Sylvester, \& Martin, 2010).

Research on student-led IEPs suggests that students with EBD can be productively involved in their IEP meetings. For example, Snyder and Shapiro (1997) and Snyder (2002) used the Self-Directed IEP program, identified as an evidence-based practice (Test, Fowler, et al., 2009), to teach students with EBD the skills needed to participate in the development of their IEP. Research also suggest that students with EBD who completed the Self-Directed IEP feel empowered, attend and take ownership of their IEP meetings, discuss their goals and dreams about life after school, and feel more confident in reaching those goals (Sweeney, 1997).

\section{Student-led IEP: Step-by-step Guidance}


Students can take an active role in each stage of their IEP process (Test et al., 2004). However, planning and implementing student-led IEPs requires time and commitment. Below, we describe the five stages of the IEP process and step-by-step directions leading to effective implementation of student-led IEP meetings.

\section{Stage 1: Developing Background Knowledge}

In this beginning stage it is important to help students understand their disability, its impact on learning and their lives, accommodations they require, their IEP, and the IEP process in general. At this time, teachers have the students describe their disabilities by prompting them with questions (e.g., "Describe your disability.", "What effect does it have in school? What effect does it have at home and in the community?"). Teachers also help students become familiar with their IEPs by asking them to find certain information in their own IEPs, or providing a checklist of required IEP components and asking them to take an inventory. Students learn the purpose of the IEP transition meeting, associated terminology, and responsibilities of the IEP team. Teachers can provide students with copies of commonly used terms, abbreviations, and acronyms and explain the roles of different IEP team members.

Additionally, teachers need to introduce information on the laws that govern the rights of students while they are in school and after graduation. Teachers should discuss key concepts from IDEA and the Americans with Disabilities Act (ADA) and help students highlight their rights under each law. Students may be advised to keep all materials in their IEP portfolios for future reference.

During the first stage of the student-led IEP process, Eric and Mr. Adams met to ensure that Eric understood his disability and his IEP. When prompted, Eric articulated the impact of his disability on learning and shared the accommodations that helped him be successful in the 
classroom. Mr. Adams provided Eric with a copy of his IEP and a checklist of required IEP components for his review. Eric laminated several copies of commonly used IEP terms and acronyms for himself and other IEP team members (see Figure 2). He kept these copies in his IEP portfolio which he referenced during his meeting. Also crucial to initial understanding of relevant transition-oriented content, Mr. Adams and Eric reviewed Eric's rights under IDEA while in school and under ADA upon graduation. As a result of these actions, Eric understood what to anticipate in the IEP meeting and increased his familiarity with the content.

\section{$<$ INSERT FIGURE 2 HERE $>$}

\section{Stage 2: Planning for the Transition IEP Meeting}

In addition to developing general background knowledge, it is important to help students determine their strengths and needs, establish goals, and organize materials in advance of the transition IEP meeting. Teachers and students need to meet to discuss student needs and concerns in each class. Morningstar and Liss (2008) recommend that students take the lead in gathering data, interpreting results, and developing goals as this allows them to "participate in assessment planning; to advocate for themselves in interpreting results; and in planning for, and directing, their individualized transition services, goals, and needs" (p. 53). Teachers can review the results of prior assessments and discuss identified strengths and needs. Teachers can also advise students to seek input from their parents and general education teachers and add their feedback to the list of strengths and needs.

An additional critical element is student completion of transition assessments that are designed to determine student preferences and develop their vision for the future and plan realistic goals for life after school. Examples include interest and career inventories such as the Transition Planning Inventory or Life Skills Inventory. Teachers may ask the student to tell what 
he or she wants to do after graduation. After this, it is important to follow with questions like, "What is the first step toward achieving this goal?" and "What should you be doing now do get ready?" Depending on students' future plans, teachers can encourage students to visit college campuses, meet with college counselors, investigate and participate in job shadowing and other vocational programs.

This is also the time to involve students in preparing for the actual IEP meeting. Students need to write invitations to the upcoming IEP meeting and distribute these invitations to administrators, teachers, parents, and other team members prior to the meeting (see Figure 3 for an example). Teachers need to provide guidance with writing and distribution of the invitations based on individual needs.

\section{<INSERT FIGURE 3 HERE>}

In the second stage of the student-led IEP, Mr. Adams reviewed transition assessment results with Eric and highlighted his strengths and needs. Using these results, Eric wrote a list of interests and activities in which he felt he did well and areas he felt he would benefit from continued support. After, Eric shared the list with his parents and classroom teachers, and he revised it based on their input. With Mr. Adams' help, Eric completed a career inventory and developed a list of suggested career options based on his vocational preferences. Mr. Adams advised Eric to narrow down his options and prompted to delve further into the career requirements. Based on the career inventory findings, Eric opted to volunteer at a local automobile repair shop to learn relevant skills and responsibilities. At this time, Eric also wrote letters of invitation for the IEP meeting (see Figure 3) and shared them with his IEP team.

\section{Stage 3: Drafting the IEP}


Students need to be involved in drafting different components of their own IEP and assist in the process as needed. Teachers ask students to provide information about their present level of performance and write paragraphs about their strengths and needs. A template may be provided to guide students in this process (Test et al., 2004). Upon completion of the template, teachers ask students to develop "I will" statements based on their needs that can become their IEP goals (Konrad, 2008). Goals, when well written, are written in proactive terms and are specific. The goals are based on a student's present level of performance and based on meeting a student's individual needs. When writing goals that are specific, measurable, achievable, relevant, and timely (SMART; O’Neill, Conzemius, Commodore, \& Pulsfus, 2006), the IEP team responds to guided questions to create meaningful goals. See Figure 4 for details on how to develop SMART IEP goals.

\section{$<$ INSERT FIGURE 4 HERE $>$}

A critical part of Stage 3 is a student review and evaluation of all IEP sections. Teachers may give a student a copy of his or her IEP, asking the student to mark parts that he or she disagrees with and change those sections so that there is agreement. Students need to review their current progress on IEP goals and place check marks next to goals they have mastered. Teachers may give students a template to complete with a vision statement, strengths, needs, goals, and services (Konrad \& Test, 2004). By creating a list of potential services and accommodations, teachers help students become aware of available choices and learn to make effective decisions.

After students prepare draft copies of their IEPs, teachers need to encourage them to share the drafts with their parents and teachers and request their input and recommendations. Teachers need to help students prepare either a written note or an email for inviting teacher and 
parent feedback. After feedback is received, teachers and students can meet to discuss feedback from these individuals and make agreed upon IEP revisions.

In this stage, teachers also need to instruct their students how to participate in their IEP meeting (Martin et al., 2006). A pre-IEP conference may help the actual IEP meeting run more smoothly and efficiently. Therefore, teachers need to consider providing students with opportunities to practice for their IEP meetings. Teachers can utilize verbal rehearsal, role playing, and prompting as strategies for increased student involvement in IEP meetings (Test et al., 2004). Teachers may want to plan several practice sessions and provide opportunities to develop a script, allowing students to build their leadership skills and self-confidence. An example of a script for welcoming IEP team members is provided in Figure 5. An IEP portfolio can help students organize their ideas and key components, which gives students an equal opportunity for presenting data and making IEP recommendations.

\section{<INSERT FIGURE 5 HERE $>$}

In the next stage of the student-led IEP, Eric developed "I will" statements related to areas of needs, including development of vocational skills. By utilizing the SMART goals template (see Figure 4), Eric articulated his actions and plans for starting a career in automotive repair and wrote an IEP goal focused on his vocational interest. Eric felt more confident as he discussed all sections of the IEP, reviewed his progress on meeting his current IEP goals, and rehearsed leading his upcoming IEP meeting. Mr. Adams and Eric met on three occasions, which provided Eric with opportunities to develop a script (illustrated in Figure 5), practice leading his IEP meeting, advocate for his needs, and build self-confidence.

\section{Stage 4: Meeting to Finalize the IEP}


Meeting to revise and finalize the IEP plan is the fourth stage and is completed at the IEP meeting. The student acts as the leader of the IEP team who welcomes everyone, makes introductions, presents the agenda, and directs the conversation during the meeting. This stage also involves students sharing their vision and postsecondary goals. Teachers must support student participation skills not only before the IEP meeting, but during the meeting as well (Snyder, 2002). To support students at the IEP meeting, teachers may provide them with verbal or written prompts (e.g., script, index card), and/or checklists (see Figure 6).

\section{$<$ INSERT FIGURE 6 HERE>}

Research indicates that both the use of published curricula to teach students transitionrelated skills and the use of person-centered planning are effective in increasing students' involvement in their IEP meetings (Test et al., 2004). Teachers may want to get a copy of a selfadvocacy or self-determination curriculum to use with their students. The Self-Advocacy Strategy (Lancaster \& Lancaster 2003) may help students create lists of potential needs, goals, services, and accommodations. Teachers may choose to use published curricula, such as The SelfDirected IEP (Martin et al., 2006) to provide students with the skills to lead their own IEP meetings. This instructional practice is designed to encourage student self-determination that focuses on multiple sequential IEP meeting participation skills, including introductions, performance review, and goal setting. Table 1 includes the listed and other resources that teachers can access to facilitate student development in transition-oriented activities.

\section{<INSERT TABLE 1 HERE>}

Teachers may support student participation in IEP meetings by directing questions and comments to the student using language that is understandable to the student (Test et al., 2004). To help the student understand that his or her input is valued, teachers may ask the student their 
opinion first, before asking other IEP team members. After the meeting, teachers and the IEP team meeting participants need to be sure to praise the student for demonstrated efforts.

In the fourth stage, the actual IEP meeting, Eric assumed a leadership role by welcoming and introducing all IEP team members. Guided by the student-led IEP checklist (see Figure 6), Eric led the team in addressing all components of the IEP. He was able to convey the agenda, review his past and current performance, share his career interests, and discuss proposed goals. Eric told meeting participants that having a clear idea of his career path eased some of his own anxiety. During the meeting, Mr. Adams interjected and prompted Eric when he perceived Eric to be at a loss for words. Eric excitedly shared accomplishments from his volunteering experience at the automotive shop and reaffirmed his desire to pursue a career in the automobile industry after graduation. The IEP team members expressed their support of Eric's vocational goal and discussed necessary supports. Eric closed the meeting by summarizing the team's decisions and thanked all IEP team members. Mr. Adams congratulated Eric on his planning and implementation efforts and for what he perceived to be a display of confidence while leading the meeting.

\section{Stage 5: IEP Implementation}

The final stage of student involvement in the process comes during implementation of the IEP. At this time, teachers have students create a summary sheet of the main components of their IEPs. The summary sheet should include an overview of the student's disability, strengths, needs, required services, and accommodations (Konrad, 2008). After the IEP meeting, students can be encouraged to distribute these summary sheets to their general education teachers.

Students can continue practicing self-advocacy skills through real-life experiences and teacher created scenarios. For example, students may be provided with a scenario in which a 
physics teacher forgets to provide a student with a copy of class notes. Students can discuss different ways to appropriately handle the situation and practice advocating for the missed accommodation through role-playing. In this stage, it is also imperative that students learn to effectively monitor and evaluate their progress toward meeting their IEP goals. For example, teachers can meet with students before progress reports are sent home to review their advancement on the IEP goals. Teachers may prompt students to write a narrative about their advancement on each IEP goal to share this information with their parents and other IEP team members (Konrad, 2008). Teachers may also provide students with a structured worksheet to track implementation of accommodations, including test accommodations, in all classes.

In the final stage of the student-led IEP, Eric completed a summary sheet and shared it with his teachers. The sheet contained a summary of the main IEP components, including accommodations Eric needed to be successful in his general education classes. Mr. Adams and Eric continued to meet and role-played scenarios in which Eric advocated for his accommodations and also addressed his progress toward meeting his IEP goals. Eric had repeatedly stated that leading his IEP was the most memorable learning experience of the year.

\section{Conclusion}

A goal of many teachers is that their students experience success while in school and beyond. However, research documenting poor post-school experiences for students with EBD remain a concern for educators, researchers, and family members. Effective transition programs must be designed for students with EBD to provide opportunities for their positive outcomes as adults. Involving students in all stages of their IEPs can empower students to take ownership of their education, choose goals for future, and pursue those goals. Implementation of a student-led IEP process is one instructional action that can provide valuable opportunities for students with 
EBD to develop and practice self-determination, self-advocacy, and other skills critical for success in high school and beyond. A step-by-step description of the student-led IEP practice, supported by examples, can be used by educators as guidance for integrating student-led IEPs in the transition process. Strengthened transition programs for students with EBD might translate into improved outcomes and enhanced quality of life for these adolescents. 


\section{References}

Arndt, S. A., Konrad, M. and Test, D. W. (2006). Effects of the self-directed IEP on student preparation in planning meetings. Remedial and Special Education, 27, 194-207. doi: 10.1177/07419325060270040101.

Bullis, M., Moran, T., Todis, B., Benz, M., \& Johnson, M. (2002). Description and evaluation of the ARIES project: Achieving rehabilitation, individualized education, and employment success for adolescents with emotional disturbance. Career Development for Exceptional Individuals, 25(1), 41-58. doi:10.1177/088572880202500104

Carter, E. (2010). Self-determination and transition-age youth with emotional or behavioral disorders: Promising practices. In D. Cheney (Eds.), Transition of secondary students with emotional or behavioral disorders: Current approaches for positive outcomes (pp. 51-78). Champaign, IL: Research Press.

Flexer, R. W., Baer, R. M., Luft, P. and Simmons, T. J. (2008). Transition planning for secondary students with disabilities (3rd ed.). Upper Saddle River, NJ: Prentice Hall.

Hawbaker, B. W. (2007). Student-led IEP meetings: Planning and implementation strategies. Teaching Exceptional Children Plus, 3(5), 1-18.

Individuals With Disabilities Education Improvement Act of 2004. P. L. No. 108-446, 20 U.S.C (2004).

Konrad, M. (2008). 20 ways to involve students in the IEP process. Intervention in School and Clinic, 43, 236-239. doi:10.2307/30035545

Konrad, M., \& Test, D. W. (2004). Teaching middle-school students with disabilities to use an IEP template. Career Development for Exceptional Individuals, 27, 101-124. doi:10.1177/088572880402700107 
Lancaster, P., \& Lancaster, S. (2003). The self-advocacy strategy [CD ROM]. Lawrence, KS: Edge Enterprises.

Mason, C. Y., McGahee-Kovac, M., \& Johnson, L. (2004). How to help students lead their IEP meetings. TEACHING Exceptional Children, 36(3), 18-24.

doi:10.1177/004005990403600302

Mason, C. Y., McGahee-Kovac, M., Johnson, L., \& Stillerman, S. (2002). Implementing studentled IEPs: Student participation and student and teacher reactions. Career Development for Exceptional Individuals, 25, 171-191. doi:10.1177/088572880202500206

Martin, J. E., Van Dycke, J. L., Christensen, W. R., Greene, B. A., Gardner, J. E. and Lovett, D. L. (2006). Increasing student participation in their transition IEP meetings: Establishing the Self-Directed IEP as an evidenced-based practice. Exceptional Children, 72, 299316. doi: $10.1177 / 001440290607200303$

Morningstar, M. E., \& Liss, J. M. (2008). A preliminary investigation of how states are responding to the transition assessment requirements under IDEIA 2004. Career Development and Transition for Exceptional Individuals, 31(1), 48-55. doi:10.1177/0885728807313776

Newman, L., Wagner, M., Cameto, R., \& Knokey, A-M. (2009). The post-high school outcomes of adolescents with disabilities up to 4 years after high school. Retrieved from http://ies.ed.gov/ncser/pdf/20093017.pdf

O’Neill, J., Conzemius, A., Commodore, C., \& Pulsfus, C. (2006). The Power of SMART goals : using goals to improve student learning. Bloomington, IN: Solution Tree.

Rowe, D., Alverson, C., Unruh, D., Fowler, C., Kellems, R., \& Test, D. (2015). A Delphi study to operationalize evidence-based predictors in secondary transition. Career Development 
and Transition for Exceptional Individuals, 38, 113-126. doi:

$10.1177 / 2165143414526429$

Snyder, E. P. (2002). Teaching students with combined behavioral disorders and mental retardation to lead their own IEP meetings. Behavioral Disorders, 27, 340-357.

Snyder, E. P., \& Shapiro, E. S. (1997). Teaching students with emotional/behavioral disorders the skills to participate in the development of their own IEPs. Behavioral Disorders, 22, $246-259$.

Sweeney, M. A. (1997). The effects of self-determination training on student involvement in the IEP process (Doctoral dissertation). Retrieved from ProQuest Dissertations and Theses database. (UMI No. 9725019)

Test, D. W., Fowler, C. H., Richter, S. M., White, J., Mazzotti, V., Walker, A. R., Kortering, L. (2009). Evidence-based practices in secondary transition. Career Development for Exceptional Individuals, 32, 115-128. doi:10.1177/0885728809336859

Test, D. W., Mason, C., Hughes, C., Konrad, M., Neale, M., \& Wood, W. M. (2004). Student involvement in individualized education program meetings. Exceptional Children, 70, 391-412. doi:10.1177/001440290407000401

Test, D. W., Mazzotti, V. L., Mustian, A. L., Fowler, C. H., Kortering, L., \& Kohler, P. (2009). Evidence-based secondary transition predictors for improving postschool outcomes for students with disabilities. Career Development for Exceptional Individuals, 32, 160-181. doi:10.1177/0885728809346960

Trainor, A. A., Smith, S. A., \& Kim, S. (2012). Four supportive pillars in career exploration and development for adolescents with LD and EBD. Intervention in School and Clinic, 48(1), 15-21. doi:10.1177/1053451212443129 
Van Dycke, J. V., Martin, J. E., \& Lovett, D. L. (2006). Why is this cake on fire? Inviting students into the IEP process. Teaching for Exceptional Children, 38(3), 42-47. doi: $10.1177 / 004005990603800306$

Wagner, M. (2014). Longitudinal outcomes and post-high school status of students with Emotional d Behavioral Disorders. In H. M. Walker, \& F. M. Gresham (Eds.), Handbook of evidence-based practices for Emotional and Behavioral Disorders: Applications in schools (p. 86-103). New York: Guildford.

Wehmeyer, M. L. (1998). Student involvement in education planning, decision making, and instruction: An idea whose time has come. In Wehmeyer, M. L., \& Sands, D. L. (Eds.), Making it happen: Student involvement in education planning, decision making, and instruction (pp. 3-23). Baltimore: Paul H. Brookes.

Woods, L. L., Sylvester, L., \& Martin, J. E. (2010). Student-directed transition planning: Increasing student knowledge and self-efficacy in the transition planning process. Career Development for Exceptional Individuals, 33, 106-114. doi:10.1177/0885728810368056 
Table 1.

Student-led IEP and Transition Strategies and Resources

Additional Web Resources

- Whose Future Is It Anyway?*

http://www.rytmus.org/shared/clanky/767/Whose\%20future\%20is\%20it\%20anyway.pdf

- Check and Connect*

http://www.checkandconnect.org/resources.html

Student-Led IEPs: A guide for student involvement

https://files.eric.ed.gov/fulltext/ED455623.pdf

http://www.checkandconnect.org/resources.html

- Self-determination lesson plan starters https://transitionta.org/lessonplans

- Transition assessment inventory toolkit: https://transitionta.org/transitionplanning

- Career development activities: www.ncwd-youth.info

- National Technical Assistance Center on Transition toolkit

https://www.transitionta.org/toolkit-resources

- Resources at the Zarrow Center http://www.ou.edu/content/education/centers-andpartnerships/zarrow.html

- Resources at the Beach Center http://www.beachcenter.org/default.aspx? JScript=1

Note: Evidence-based instructional strategies (Test, Fowler, et al., 2009) are denoted with an asterisk. 

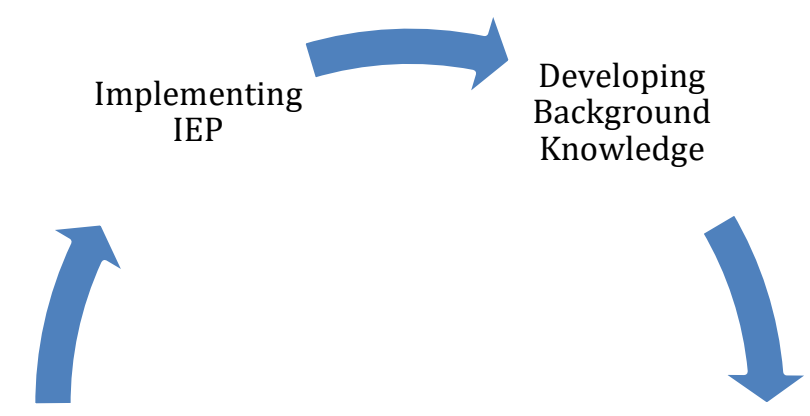

IEP Meeting Planning IEP

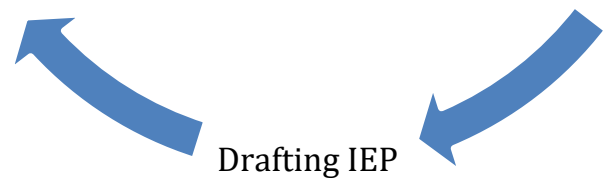

Figure 1. Stages of the IEP process. Adapted from 20 Ways to Involve Students in the IEP Process (Konrad, 2008). 


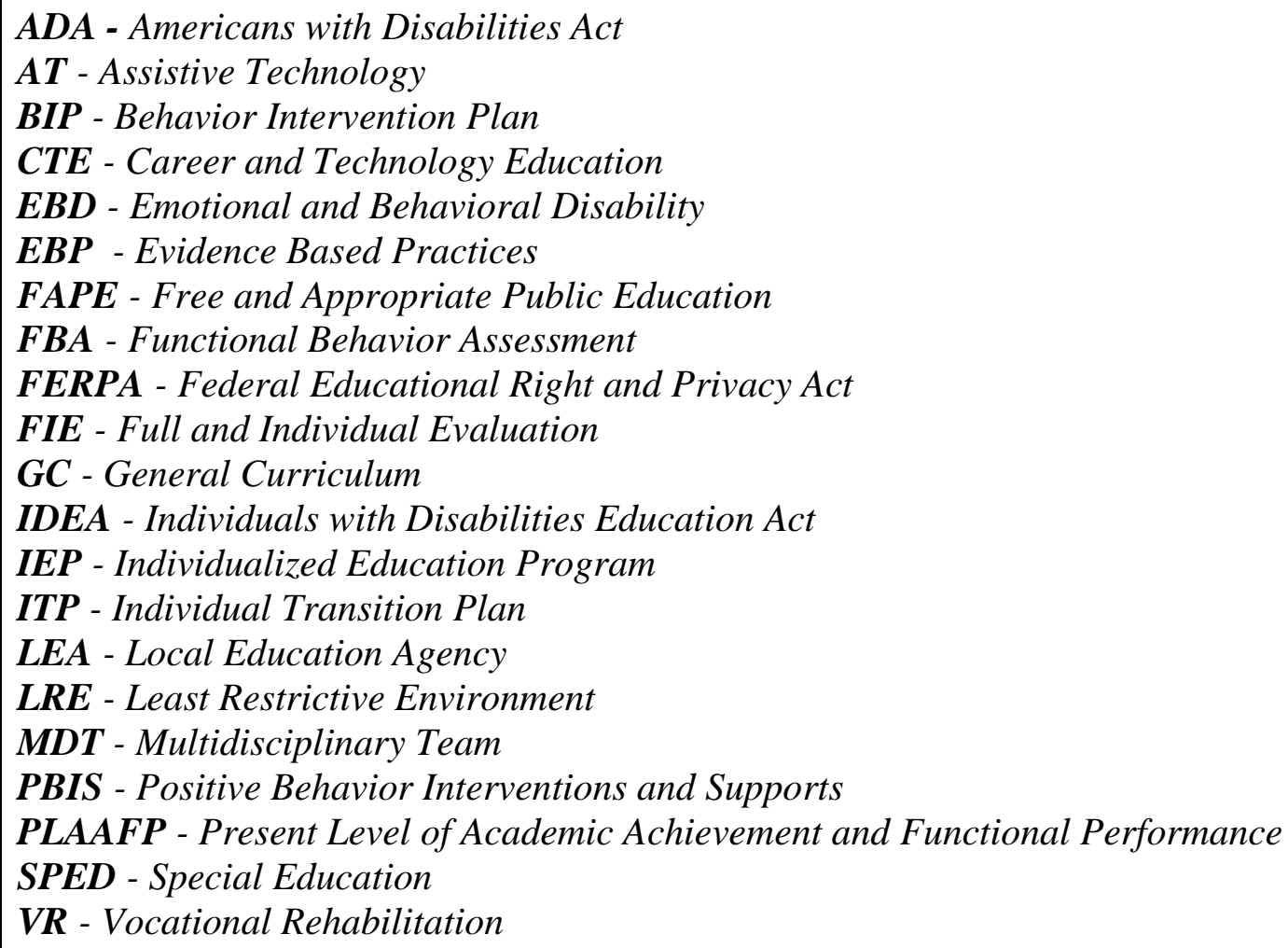

Figure 2. Examples of the commonly used IEP terms and acronyms. 
Dear Ms. Snow,

You are invited to attend my Individualized Education Program (IEP) team. The meeting will take place in the conference room at 9:00 am on January 18, 2019.

In this meeting, I will share information about my strengths, weaknesses, and IEP goals. I will also share my dreams for life after school and how I plan to achieve them. My IEP meeting is very important to me and I hope you will be able to attend.

Thank you,

Eric Kowalski

Figure 3. Example of an IEP invitation letter. 


\section{Eric's SMART goal:}

Eric will work with a career counselor at the vocational school to identify at least two programs that will lead to industry certifications in auto repair and be able to describe their similarities and differences by creating a Venn Diagram for his case manager by his next IEP meeting.

Specific goals lay out the specific things you plan to accomplish:

What do you want to accomplish and why? I want to get a job in automobile repair because I really like to work with my hands. Working on cars is like working on a puzzle with a bunch of pieces that can perfectly fit together. Once finished, or repaired, it can be perfect.

How are you going to do to accomplish this goal? I will meet with a counselor at the vocational school that has special programs in auto body and engine repair and select two programs I like the most. I still like to volunteer in the auto body shop so I can learn more.

Measurable goals have concrete criteria for measuring progress:

How will you know when you have achieved this goal? I'll know I achieved this goal when I discuss similarities and differences of the two programs with Mr. Adams and make a Venn Diagram.

Achievable goals can be actually reached by putting forth efforts and asking for help:

Is this goal realistic? I think it is achievable. My dad is finally $O K$ with me going to the technical school. He knows I like it a lot. Also, cars are my passion and I want to work on cars more than anything.

Do you have all necessary supports to achieve it? Yes. It's pretty cool because lately a lot of people, teachers, my guidance counselor, Mr. Adams and my friends are really encouraging me to go for it.

Relevant goals are goals that are important to your life and matter to you now:

Why is this goal important to you? I think it is a really good goal to set me on my career path. There will always be cars that need to be repaired. The money is pretty good and I can support myself and maybe someday a family. I may even want to own my own shop.

Timely goals set a target date (e.g., days, weeks, months, etc.) for you to reach your goals:

When can you achieve this goal? I'm going to talk with a counselor at the tech school and then tell Mr. Adams about my choices in programs before our next pre-IEP meeting.

Figure 4. Setting SMART goals. Adapted from the University of Minnesota

(www.checkandconnect.org) 
Hello everyone,

Welcome to my IEP meeting! As you all know, my name is Eric Kowalski and I am a junior student here at Vista Ridge High School. First, I want to thank you for coming to my IEP meeting. Next, I would like to introduce the IEP team members. Most of you have met my mother, Mrs. Kristy Kowalski. This is my English teacher, Ms. Wanda Snow. Mr. Hough Adams is my Special Education teacher and my case manager. Dr. Art Watson is my Assistant Principal. This is my counselor Ms. Judy Peters.

My IEP is very important to me: it helps me to learn and master skills for future employment. Today, we will review my past goals and performance and hear about my interests, strengths, and areas of needs. We will also review my current progress, develop my new goals, and discuss supports that will help me master my IEP goals and achieve my postschool goal to become an auto mechanic.

Figure 5. Starting the IEP meeting script. 


\begin{tabular}{|l|l|}
\hline \multicolumn{2}{|c|}{ Student-led IEP Checklist } \\
\hline Checklist items & Checkmark \\
\hline 1. Starting the Meeting & \\
\hline a. Introduce yourself and all attendees & \\
\hline b. State the purpose of the IEP meeting & \\
\hline \multicolumn{2}{|c|}{} \\
\hline 2. Leading the Meeting & \\
\hline a. Review past goals and performance & \\
\hline b. Review current performance and progress & \\
\hline c. Report interests, strengths, and areas of needs & \\
\hline d. Describe post-school goals & \\
\hline e. Review necessary supports & \\
\hline & \\
\hline 3. Closing the Meeting & \\
\hline a. Summarize decisions & \\
\hline b. Thank participants and shake their hands & \\
\hline c. Close the meeting & \\
\hline
\end{tabular}

Figure 6. Student-led IEP checklist. 